\title{
Evaluation of the SF-36 questionnaire for assessment of the quality of life of endometriosis patients undergoing treatment: A systematic review and meta-analysis
}

\author{
ROMINA-MARINA SIMA ${ }^{1,2^{*}}$, LIANA PLEŞ ${ }^{1,2^{*}}$, BOGDAN SOCEA $^{3,4}$, PANAGIOTIS SKLAVOUNOS $^{5}$, \\ IONUŢ NEGOI $^{3,6}$, ANCA-DANIELA STĂNESCU ${ }^{1,2}$, IOAN-IULIAN IORDACHE ${ }^{5}$, BASHAR HAJ HAMOUD ${ }^{5}$, \\ MARC PHILLIP RADOSA ${ }^{7}$, INGOLF JUHASZ-BOESS ${ }^{5}$, ERICH FRANZ SOLOMAYER ${ }^{5}$, MIHAI C.T. DIMITRIU ${ }^{1,8}$, \\ CĂTĂLIN CÎRSTOVEANU ${ }^{9,10}$, DRAGOŞ ŞERBAN ${ }^{3,11}$ and JULIA CAROLINE RADOSA ${ }^{5}$ \\ ${ }^{1}$ Department of Obstetrics and Gynecology, 'Carol Davila' University of Medicine and Pharmacy, 020021 Bucharest; \\ ${ }^{2}$ Department of Obstetrics and Gynecology, 'Sf. Ioan' Hospital, Bucur Maternity, 040294 Bucharest; \\ ${ }^{3}$ Department of Surgery, 'Carol Davila' University of Medicine and Pharmacy, 020021 Bucharest; ${ }^{4}$ Department of Surgery, \\ 'Sf. Pantelimon' Emergency Hospital, 021659 Bucharest, Romania; ${ }^{5}$ Department of Gynecology, Obstetrics and \\ Reproductive Medicine, Saarland University Hospital, D-66421 Homburg, Germany; ${ }^{6}$ Department of Surgery, \\ Clinical Emergency Hospital of Bucharest, 014461 Bucharest, Romania; ${ }^{7}$ Department of Gynecology, \\ University Hospital Leipzig, D-04103 Leipzig, Germany; ${ }^{8}$ Department of Obstetrics and Gynecology, \\ 'Sf. Pantelimon' Emergency Hospital, 021659 Bucharest; ${ }^{9}$ Department of Pediatrics, \\ 'Carol Davila' University of Medicine and Pharmacy, 020021 Bucharest; ${ }^{10}$ Pediatrics Department, \\ 'Maria Sklodowska Curie' Emergency Children Clinical Hospital, 041451 Bucharest; \\ ${ }^{11}$ Department of Surgery, University Emergency Hospital, 050098 Bucharest, Romania
}

Received July 16, 2021; Accepted August 16, 2021

DOI: $10.3892 /$ etm.2021.10718

\begin{abstract}
Endometriosis has a negative influence on the physical, psychological, and social aspects of a patient's life; therefore, it affects the health-related quality of life (HRQoL). The current review aimed to investigate the efficiency of a 36-item generic questionnaire survey (SF-36) for patients with endometriosis who were undergoing medical or surgical treatment. A search strategy including the key words 'endometriosis', 'quality of life' (QOL), and 'questionnaire SF-36' was applied using the PubMed/MEDLINE, EMBASE, and Cochrane databases in order to include articles that evaluated the QOL among women with endometriosis using the SF-36. Only articles that included interviews of patients both before and after surgical or medical endometriosis treatment or those articles that compared study groups were considered. The qualitative analysis was based on 37 articles, whereas the quantitative analysis utilized 14 articles.
\end{abstract}

Correspondence to: Dr Bogdan Socea, Department of Surgery, 'Carol Davila' University of Medicine and Pharmacy, 37 Dionisie Lupu Street, 020021 Bucharest, Romania

E-mail: bogdan.socea@umfcd.ro

*Joint senior authorship

Key words: endometriosis, quality of life, SF-36, endometriosis therapy, laparoscopy
The research participants included 11,101 women, among whom 6,888 patients were diagnosed with endometriosis. The analysis recorded 17 studies dealing with all types of endometriosis, 9 studies dealing with deep infiltrative endometriosis (DIE), and 9 studies dealing with bowel endometriosis or DIE with bowel involvement. QOL was evaluated using only SF-36 in 12 studies that collectively included 1,912 women and using SF-36 in association with other questionnaires in 25 studies that collectively included 8,022 women. For patients with endometriosis, physical functioning [odds ratio (OR), 78.87; 95\% confidence interval (CI), 68.97-88.77; $\left.\mathrm{I}^{2}=98.77 \% ; \mathrm{P} \leq 0.001\right]$ was the most affected life parameter. This parameter showed the highest improvement after surgical intervention (OR, 63.39; 95\% CI, 48.71-78.07; $\left.\mathrm{I}^{2}=97.65 \% ; \mathrm{P} \leq 0.001\right)$ or hormonal treatment $(\mathrm{OR}$, 38.65; 95\% CI, 14.39-62.91; $\mathrm{I}^{2}=38.65 \%$; $\left.\mathrm{P} \leq 0.001\right)$. The 36 -item survey generic questionnaire seems to be an efficient tool for assessment of the QOL of life of women with endometriosis who are undergoing surgical or medical treatment. It can be applied before and after the procedure, and it can also be used for comparing study groups.

\section{Contents}

1. Introduction

2. Research methods

3. Results of the study research

4. Discussion 


\section{Introduction}

Endometriosis is a condition resulting from ectopic endometrial cell implants that grow progressively and determine an inflammatory response (1). The ovaries are the most common locations for endometriotic lesion formation, followed by the anterior and posterior cul-de-sac, the posterior surface of the broad ligaments, the uterosacral ligaments, the serosa of the uterus, the fallopian tubes, the sigmoid colon, the appendix, and the round ligament (2). The therapeutic options are based on clinical presentation, including infertility, pain, or mass; they are individualized according to disease severity, patient age, and reproductive desires while considering the medication side effects, costs and morbidity of the surgical procedures $(3,4)$.

Endometriosis negatively affects the physical, psychological, and social aspects of women's lives (5), and therefore has a great an impact on the health-related quality of life (HRQoL). It is difficult to characterize the quality of life (QOL) among specific patient groups because it is a broad concept that includes life satisfaction, good health, education, personal and family safety, adequate housing, employment, interrelationships, and leisure pursuits (6). Globally, in the scientific literature, QOL is evaluated using a multitude of validated and non-validated questionnaires, such as the 36-item survey generic questionnaire (SF-36). It includes eight conceptual health domains: General Health (GH), Physical Functioning (PF), Bodily Pain (BP), Role Physical (RP), Vitality (VT), Social Functioning (SF), Mental Health (MH), and Role Emotional (RE); these are summarized in the physical (PCS) and mental (MCS) component scores (7).

Recently, a number of original studies and systematic reviews have evaluated the impact of endometriosis on patient QOL (8-10). Studies have also reported the impact of different therapeutic approaches on the QOL of patients with endometriosis (11). A systematic review detailed the quality of sexual life after endometriosis-targeted laparoscopic surgery (12). Another recent meta-analysis showed that endometriosis-targeted surgical resection can improve the major domains of QOL (13). However, systematic reviews that evaluate the impact of surgical and non-surgical treatments on the QOL of patients with endometriosis are scarce.

The main objective of the present review was to investigate the efficiency of questionnaire SF-36 in assessing the QOL of patients with endometriosis who were undergoing medical or surgical treatment.

\section{Research methods}

We utilized the 'Preferred Reporting Items for Systematic Reviews and Meta-Analyses (PRISMA)' guideline to conduct this study' (14).

Data sources and search strategies. A combination of key word terms including 'endometriosis', 'quality of life' and 'questionnaire SF-36' were utilized for the literature research conducted in October 2018. The utilized databases included PubMed/Medline, Embase, and Cochrane; some other additional sources and references of the identified articles were also utilized. The search strategy that was utilized for PubMed/MEDLINE is outlined as follows.
Study selection. Articles that evaluated the quality of life (QOL) and used the SF-36 to assess women with endometriosis were evaluated. Articles that interviewed patients both before and after endometriosis-related surgical or medical treatment were included in our analysis. We also utilized the reports of women with endometriosis that were compared with a control group. Studies that focused on any type of endometriosis and were published in English, German, or French were considered in our analysis. There were no restrictions based on publishing year, journal, author, or institution.

Data extraction. All the selected studies were independently evaluated by two reviewers. Any disagreements regarding the articles were solved by the third more experienced author and the senior authors. The data were extracted in tables that consisted of first author's name, publication year, study type, number of initial participants, treatment type, presence of a control group or lack thereof, endometriosis type, treatment, follow-up, and the final number of participants.

Quality assessment. To evaluate the quality of the included studies, the modified Newcastle-Ottawa Scale (NOS) was applied (15). This scale helped to assess the risk of bias in the remaining studies. The studies were classified as 'good' when they fulfilled at least $70 \%$ of the 12 criteria, 'fair' when they fulfilled at least 50\%, and 'poor' when they fulfilled less than $50 \%$.

Statistical analysis. Since we observed between-study heterogeneity, we applied random-effects meta-analyses, using odds ratios (OR) and $95 \%$ confidence intervals $(95 \% \mathrm{CI})$. The results were presented as pooled prevalence values. Studies that reported data by comparing various endometriosis types were included in the data for the most severe, whereas studies that dealt with different types of surgical treatment were considered the most difficult interventions. Statistical analysis was performed using the Open-Meta analyst [CEBM Brown, open-source, OpenMetaAnalyst for Windows 10 (64-bit)].

In our study, statistical results were calculated as follows. The first report was based on a comparison between patients with endometriosis and a control group (healthy women); the second considered surgical treatment, and the third group considered hormonal treatment.

\section{Results of the study research}

Study research. In accordance with our research plan, we initially identified the records of 657 articles that corresponded to our search strategy. Furthermore, 25 articles were sourced generated from additional sources (cross references). Any duplicates were removed, and the final database consisted of 345 articles. Excluding some articles due to language issues, we obtained reviews, case reports, or abstracts from 127 records for screening. Among these, 55 studies were excluded based on the inclusion criteria. Finally, full-text evaluation was conducted for 72 studies. The qualitative analysis was based on 37 articles, whereas the quantitative analysis utilized 14 articles.

Regarding the study types, our qualitative analyses included 21 prospective studies, 3 retrospective studies, 
and 7 randomized clinical trials. A total of 25 studies that associated other questionnaires with the SF-36 to evaluate the QOL of patients with endometriosis were identified.

Based on our study protocol, we observed that 13 studies did not apply the SF-36 questionnaire before and after treatment. The results were specified only in the graphics and not in the text. Some studies reported the results as a total number; thus, it was impossible to include them in the statistics. Only studies that had all the reported numerical data from the questionnaires were selected for the meta-analyses.

Quality and the risk of bias. Based on the inclusion criteria, we obtained 37 studies; among these, 16 articles were considered as being of 'good' quality (between 6 and 8 points), and 11 articles were considered as being of 'fair' quality (between 3 and 5 points). Table I includes evaluations for each study.

Study characteristics. The characteristics for each study are recorded in Table II. The research included 1,1101 women, among whom 6,888 patients were diagnosed with endometriosis. Based on the endometriosis type, 17 studies dealt with all types of endometriosis, 9 studies focused on deep infiltrative endometriosis, and another 9 studies identified bowel endometriosis or deep infiltrative endometriosis with bowel involvement. QOL was evaluated by using only the SF-36 in 12 studies including 1,912 women and by using SF-36 associated with various other questionnaires in 25 studies that had a collective total of 8,022 women.

As part of the SF-36 questionnaire's general evaluation, it was applied for studies that presented the QOL of the patients with endometriosis in comparison to that of healthy women or patients with endometriosis that were interviewed using SF-36 just once (without any follow-up period). Based on this classification, the review included 15 studies with a general overview on endometriosis. Among them, 6 studies evaluated the QOL of patients with endometriosis compared with that of healthy women, and 9 studies compared different types of treatment among patients with endometriosis. On this topic, 6,810 women were evaluated, and 6,393 had endometriosis. The classification based on endometriosis subtypes confirmed that 5,410 patients had all the endometriosis types, 416 had deep infiltrative endometriosis (DIE), and 198 had minimal endometriosis.

For this group of the review, the quantitative analysis could be performed in 6 studies. Our study revealed that patients with endometriosis had an altered QOL compared to the control healthy women group. The pooled prevalence showed that the selected parameters were influenced as follows: Physical Functioning (PF): OR, 78.87 (95\% CI, 68.97-88.77; $\mathrm{I}^{2}=98.77 \%$; $\mathrm{P} \leq 0.001)$; Bodily Pain (BP): OR, 51.63 (95\% CI, 45.23-58.03; $\mathrm{I}^{2}=92.62 \%$; $\left.\mathrm{P} \leq 0.001\right)$; Role Physical (RP): OR, 56.12 (95\% CI, 45.08-67.12; $\mathrm{I}^{2}=95.40 \%$; P $\leq 0.001$ ); Vitality (VT): OR, 43.09 (95\% CI, 32.23-53.95; $\left.\mathrm{I}^{2}=98.67 \% ; \mathrm{P} \leq 0.001\right)$; Social Functioning (SF): OR, 58.10 (95\% CI, 47.28-68.91; $\mathrm{I}^{2}=97.67 \%$; $\mathrm{P} \leq 0.001$ ); Mental Health (MH): OR, 55.65 (95\% CI, 45.58-65.72; $\mathrm{I}^{2}=98.41 \%$; $\left.\mathrm{P} \leq 0.001\right)$; and Role Emotional (RE): OR, 57.84 (95\% CI, 47.21-68.48; $\mathrm{I}^{2}=95.19 \%$; $\mathrm{P} \leq 0.001$ ). Based on poled prevalence, for patients with endometriosis, the most affected parameter was Physical Functioning (PF): OR, 78.87 (95\% CI, 68.97-88.77; $\left.\mathrm{I}^{2}=98.77 \% ; \mathrm{P} \leq 0.001\right)$.
Qualitative analysis regarding QOL for patients that underwent surgical treatment for endometriosis was evaluated with a SF-36 tool, and it included 21 studies with a collective population of 3,368 patients (Table III). In all the selected studies, the questionnaire was completed before and after surgery. The various studies' follow-up periods ranged between 7 weeks and 3 years. The types of endometriosis were all types of endometriosis (3 studies), DIE (14 studies), or intestinal endometriosis (3 studies). Statistical analyses were performed for 5 studies that included mean values for each result. The studies confirmed that the parameters evaluated with SF-36 improved after surgical treatment. Pooled prevalence revealed that each parameter improved as follows: Physical Functioning (PF): OR, 63.39 (95\% CI, 48.71-78.07; $\left.\mathrm{I}^{2}=97.65 \% ; \mathrm{P} \leq 0.001\right)$; General Health $(\mathrm{GH})$ : OR, -0.71 (95\% CI, -1.20--0.23; $\mathrm{I}^{2}=90.04 \%$; $\left.\mathrm{P} \leq 0.001\right)$; Bodily Pain (BP): OR, 41.25 (95\% CI, 38.95-43.55; $\mathrm{I}^{2}=97.33 \%$; $\left.\mathrm{P} \leq 0.001\right)$, Role Physical (RP): OR, 43.16 (95\% CI, 32.74-53.58; $\mathrm{I}^{2}=91.83 \%$; $\mathrm{P} \leq 0.001$ ); Vitality (VT): OR, 37.99 (95\% CI, 30.54-45.44; $\mathrm{I}^{2}=93.45 \%$; $\left.\mathrm{P} \leq 0.001\right)$; Social Functioning (SF): OR, 48.09 (95\% CI, 30.67-63.50; $\mathrm{I}^{2}=98.69 \%$; P $\leq 0.001$ ); Mental Health (MH): OR, 51.78 (95\% CI, 44.70-58.87; $\mathrm{I}^{2}=92.73 \%$; $\left.\mathrm{P} \leq 0.001\right)$; and Role Emotional (RE): OR, 50.65 (95\% CI, 41.37-59.93; $\mathrm{I}^{2}=88.39 \%$; $\left.\mathrm{P} \leq 0.001\right)$. In the case of patients who had their endometriosis surgically treated, among the parameters evaluated by SF-36, the highest rate of improvement was observed in Physical Functioning (PF): OR, 63.39 (95\% CI, 48.71-78.07; $\left.\mathrm{I}^{2}=97.65 \% ; \mathrm{P} \leq 0.001\right)$.

Quantitative analysis was conducted for 7 studies on patients who underwent hormone treatments, which were evaluated with SF-36, whereas the statistic forest plots were based on 3 studies. The patients with endometriosis (392 in number) were compared with a control group that did not receive the same treatment (placebo or control). The studies showed that parameters evaluated with SF-36 improved after hormonal treatment. Pooled prevalence revealed that each parameter improved as follows: Physical Functioning (PF): OR, 38.65 (95\% CI, $14.39-62.91 ; \mathrm{I}^{2}=38.65 \%$; $\left.\mathrm{P} \leq 0.001\right)$; General Health (GH): OR, -0.60 (95\% CI, -1.78-0.57; $\mathrm{I}^{2}=94.13 \%$; $\leq 0.001$ ); Bodily Pain (BP): OR, 28.51 (95\% CI, 10.05-41.96; $\mathrm{I}^{2}=97.33$; $\mathrm{P} \leq 0.001)$; Role Physical (RP): OR, 32.42 (95\% CI, 0.62-64.49; $\mathrm{I}^{2}=98.62 \%$; $\left.\mathrm{P} \leq 0.001\right)$; Vitality (VT): OR, 31.49 (95\% CI, 6.58-56.39; $\left.\mathrm{I}^{2}=98.58 \% ; \mathrm{P} \leq 0.001\right)$; Social Functioning (SF): OR, 35.86 (95\% CI, 12.01-59.7; $\mathrm{I}^{2}=97.92 \%$; $\left.\mathrm{P} \leq 0.001\right)$; Mental Health (MH): OR, 35.11 (95\% CI, 5.72-64.50; $\mathrm{I}^{2}=98.85 \%$; $\mathrm{P} \leq 0.001$ ); and Role Emotional (RE): OR, -0.39 (95\% CI, $-0.90-0.20 ; \mathrm{I}^{2}=74.57 \%$; $\left.\mathrm{P} \leq 0.001\right)$. After the hormonal treatment, the parameter that showed the most improvement was Physical Functioning (PF): OR, 38.65 (95\% CI, 14.39 -62.91; $\mathrm{I}^{2}=38.65 \%$; $\left.\mathrm{P} \leq 0.001\right)$.

\section{Discussion}

Our meta-analyses revealed that the SF-36 questionnaire had a heterogenous applicability in all the studies. Recently, Chauvet et al performed a recent systematic review, which proved that the SF-36 was the most frequently used scale, followed by the EHP-30, for evaluating quality of life (QOL) of patients with endometriosis (16). The design of our study was different from previous meta-analyses as we included articles 


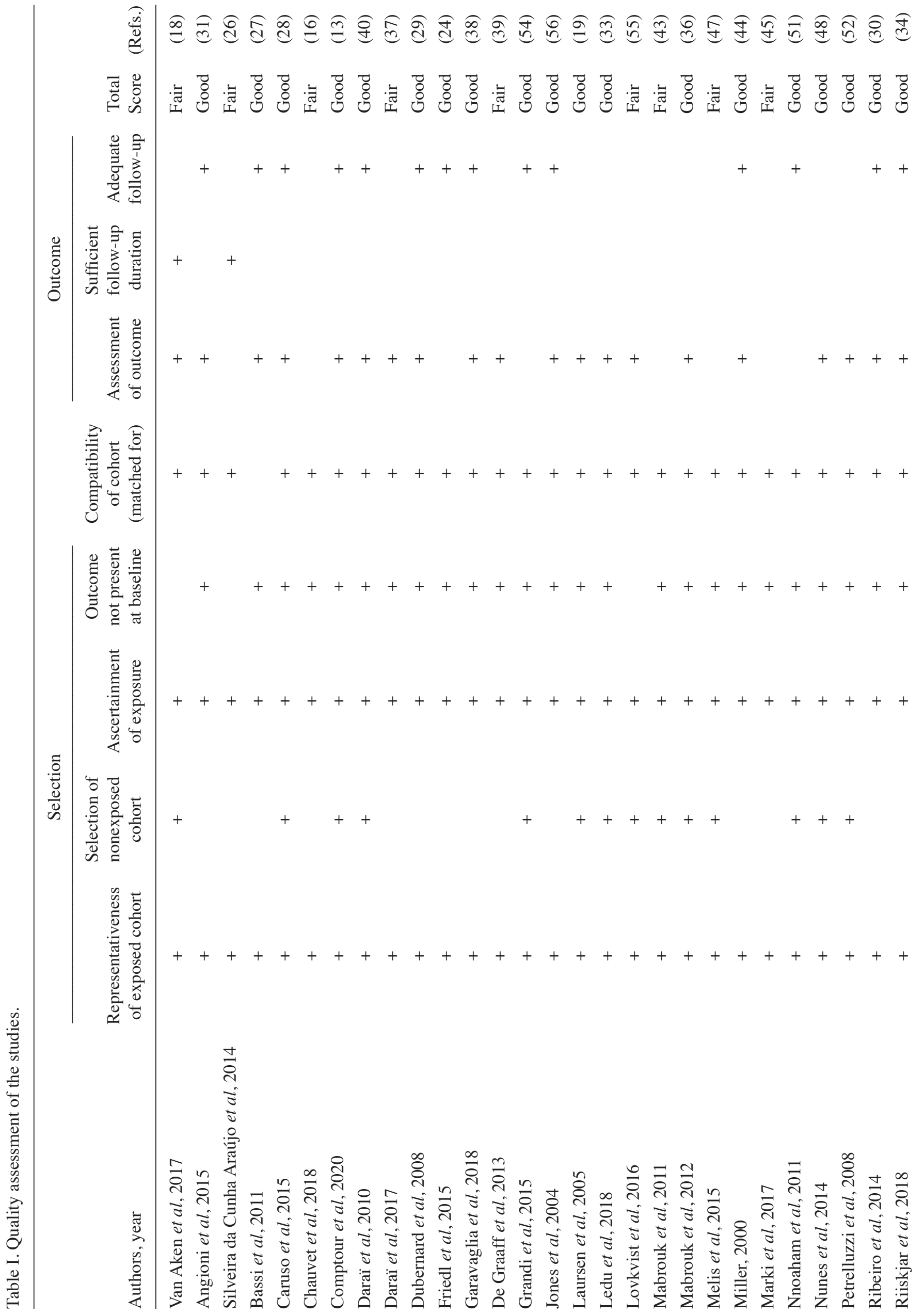




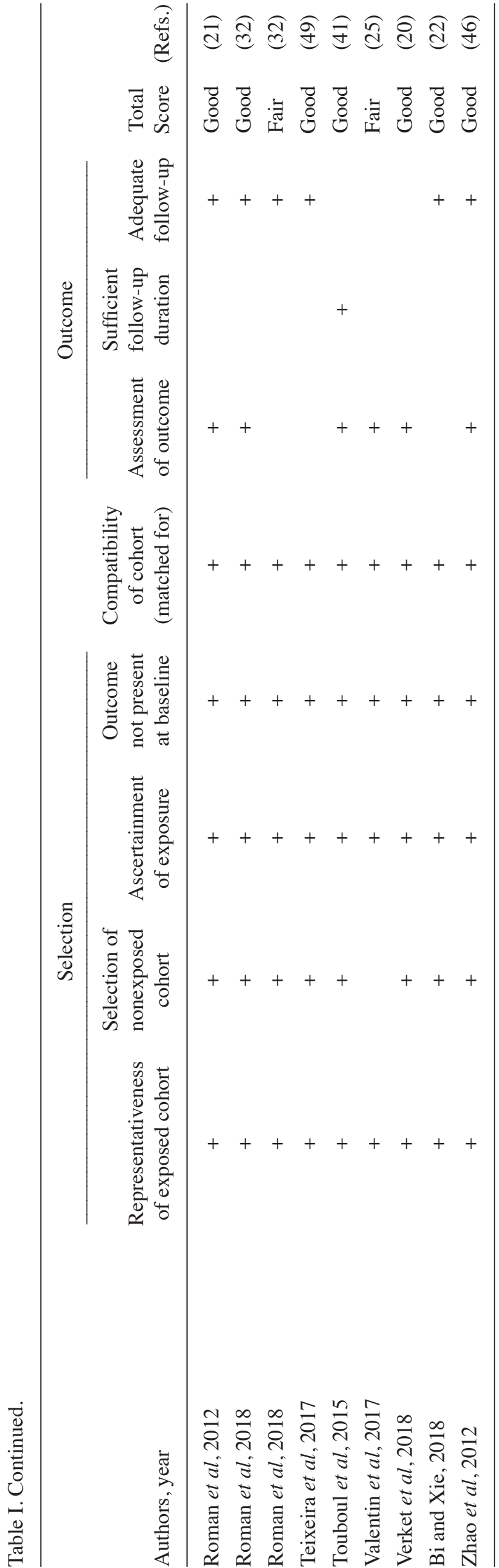

that evaluated patients with endometriosis using the SF-36 questionnaire before and after surgical or medical treatment or as a comparison tool between groups. The literature did not reveal a similar approach. For example, Arcoverde et al performed another meta-analysis utilizing generic questionnaires and revealed that surgery improved the quality of life for patients with all types of endometriosis (17). We excluded cases with hormonal approach and cases that were evaluated using different questionnaires (18). There was no meta-analyses that evaluated the efficiency of SF-36 for patients with endometriosis treated with hormonal therapy or as a comparison method between study groups.

Regarding the first issue of our classification, we identified 6,393 women who received treatment for endometriosis and answered the SF-36 questionnaire. Based on this approach, we observed that, for women with endometriosis, compared with the control groups, physical functioning was the main parameter that received the most alteration. Two peculiar studies were included within this group of studies. Laursen et al (19) compared patients with fibromyalgia/whiplash, endometriosis, lower back pain, or rheumatoid arthritis and healthy women. We included this study because of its data accuracy; furthermore, there was no other pathological influence on the women with endometriosis. The second study was the Verket et al study (20), which evaluated women from the general population, women with endometriosis, and women with rheumatoid arthritis. We incorporated it into the analyses of this study because it did not have a control group of healthy women for comparison to women with endometriosis, and the arthritis had no impact. For both of these studies, we considered only the data for the endometriosis patients.

Van Aken et al demonstrated that, for endometriosis patients, pain cognition and QOL are independently associated (18). Verket et al highlighted that patients with moderate to severe endometriosis had overall impaired QOL compared to women from the general population (20). Women with DIE reported constipation, defecation pain, appetite disorders, longer evacuation time, and increased stool consistency without laxatives (21). Neuromuscular electro-stimulation was found to be an efficient method for alleviating endometriosis-related pain (22).

The present analysis of QOL for patients with endometriosis who received surgical treatment included data from 3,368 patients. The pre- and post-surgery questionnaire in all the studies showed that physical functioning was the principal parameter that improved after the interventions. The studies proved that endometriosis symptoms such as pain showed improvement after surgical treatment (23), even though endometriosis also influenced biopsychosocial variables (24). Patients with minimal endometriosis seldom reported surgery as a good treatment for improving QOL (25). For patients with bowel endometriosis, QOL improved significantly after laparoscopic treatment $(26,27)$, with long-term results (28-30). The study by Angioni et al (31), a randomized clinical trial, included a surgery group as well as a hormonal treatment group. For this group, we considered the arm A results, with a complete resection of DIE. The study by Roman et al (2018) (32) was analyzed with regard to the segmental resection of the rectum, and the study by Ledu et al (33) was utilized for the group consisting of patients with stoma; this was because of the 


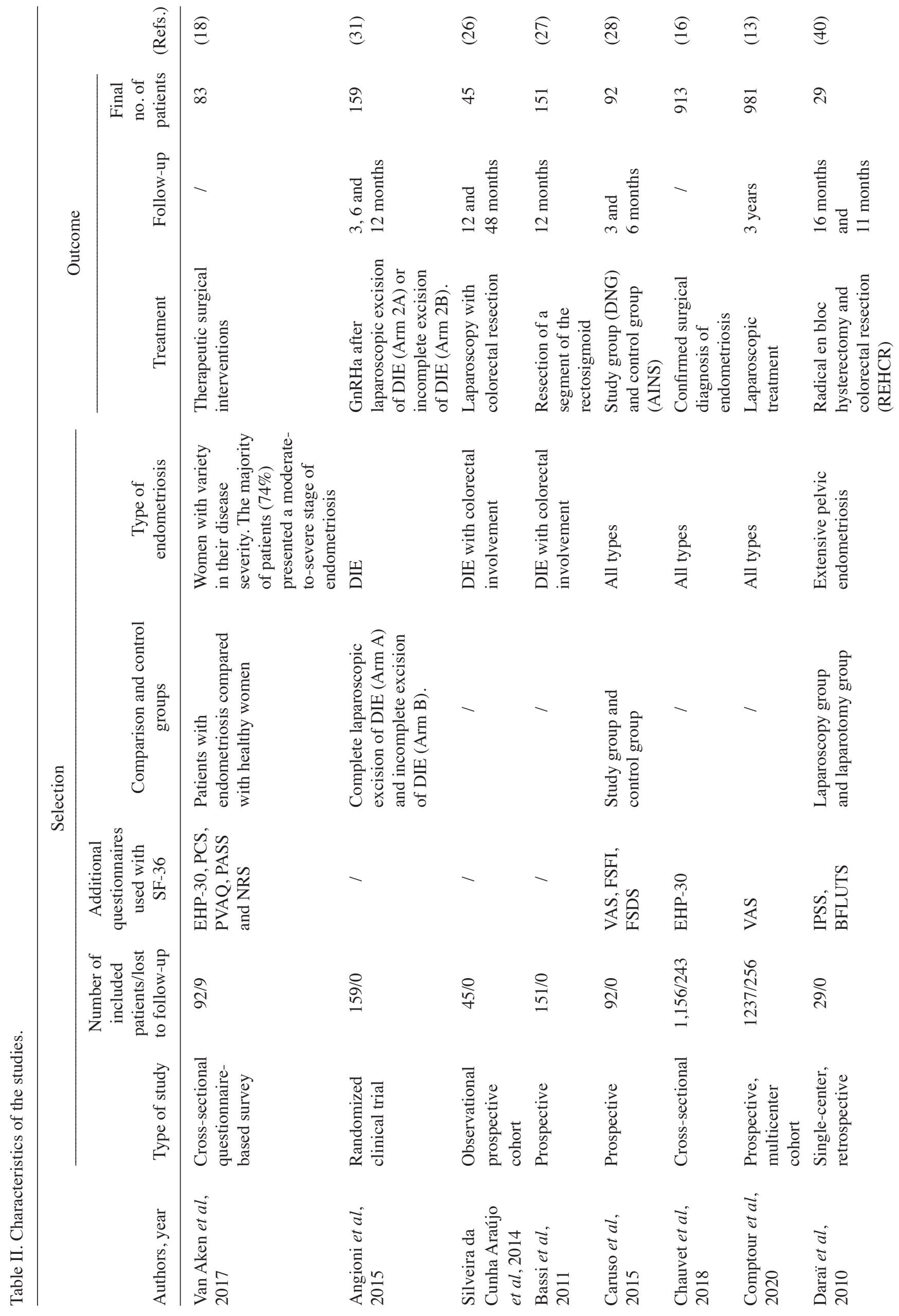




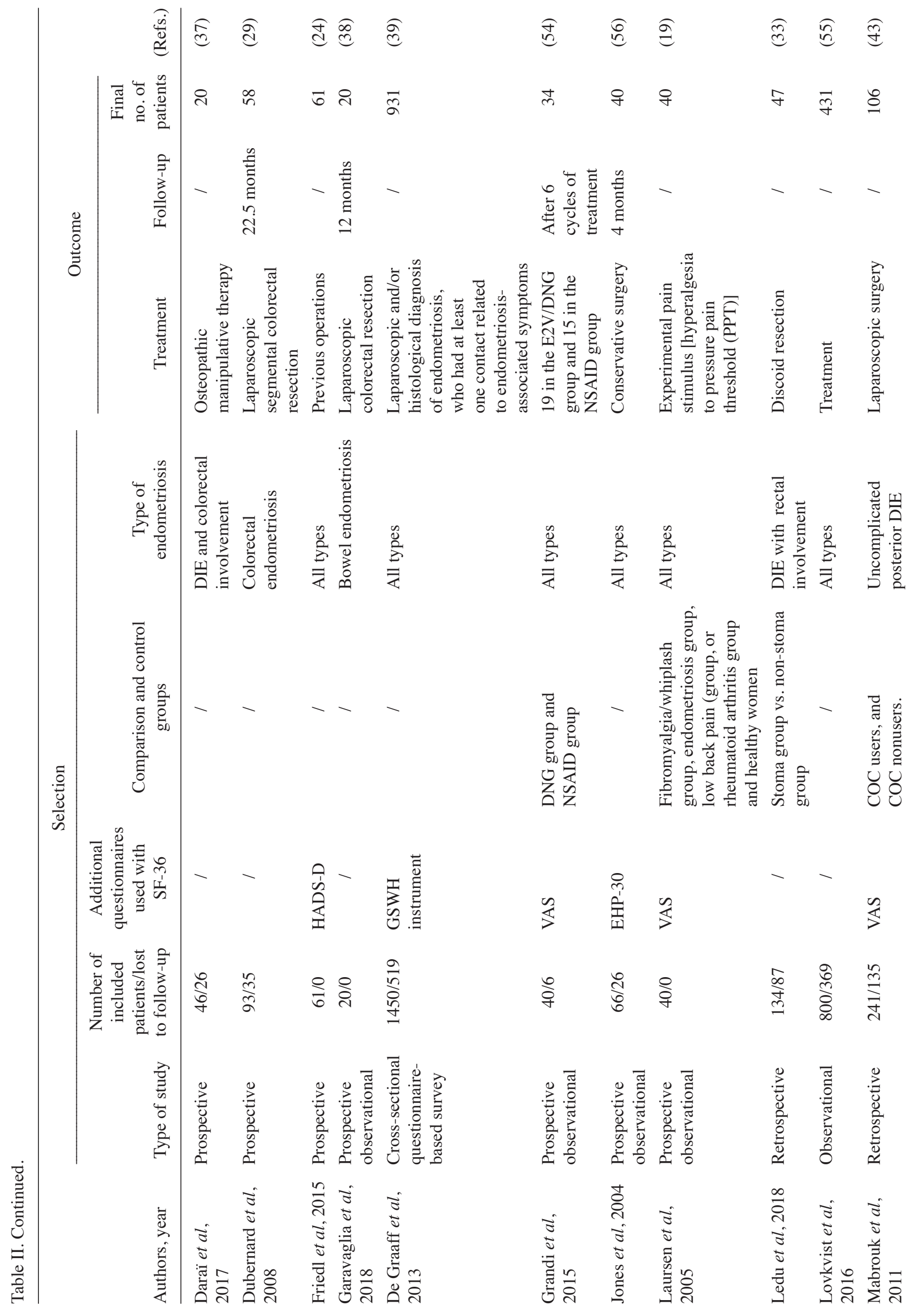




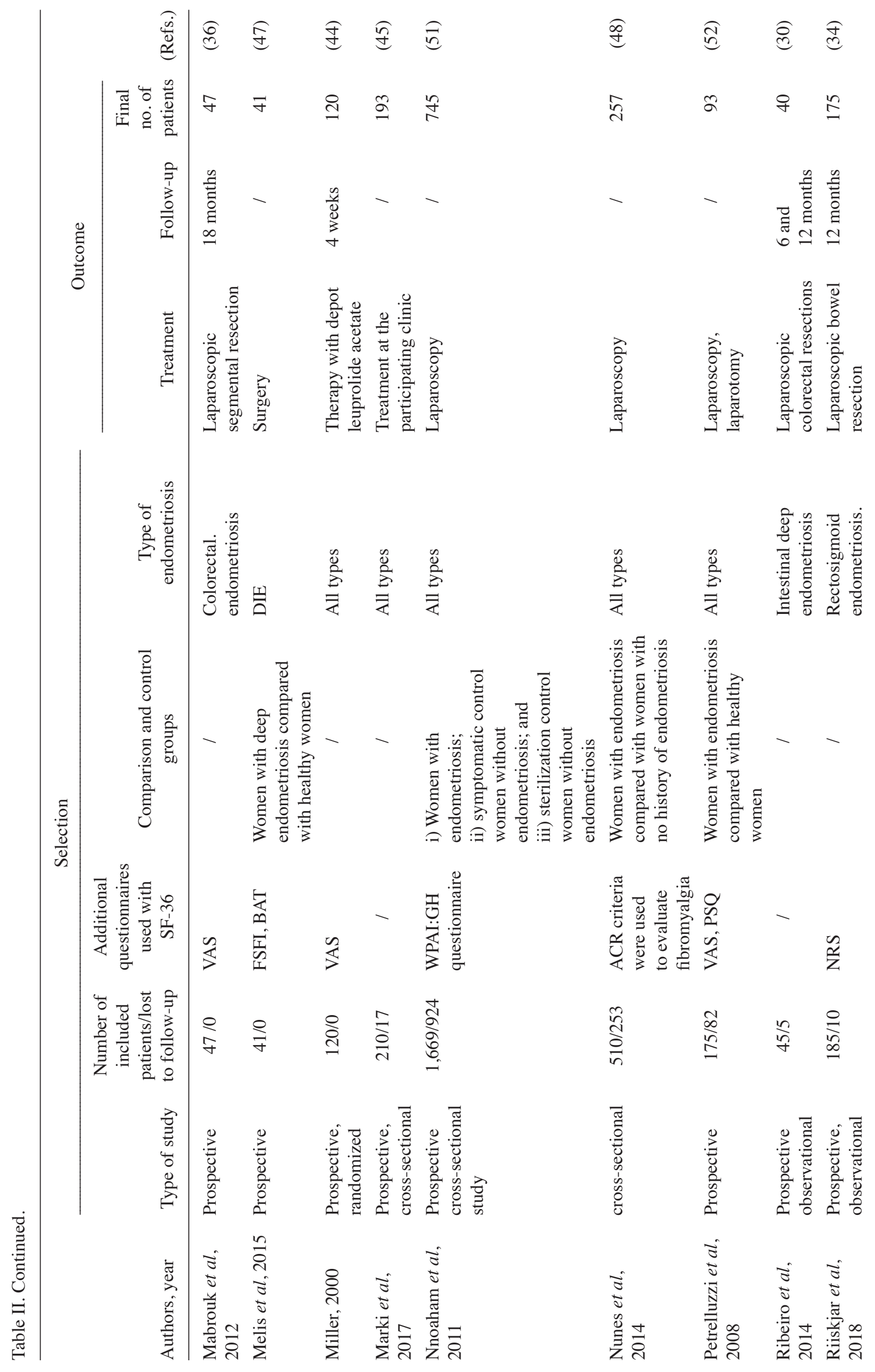




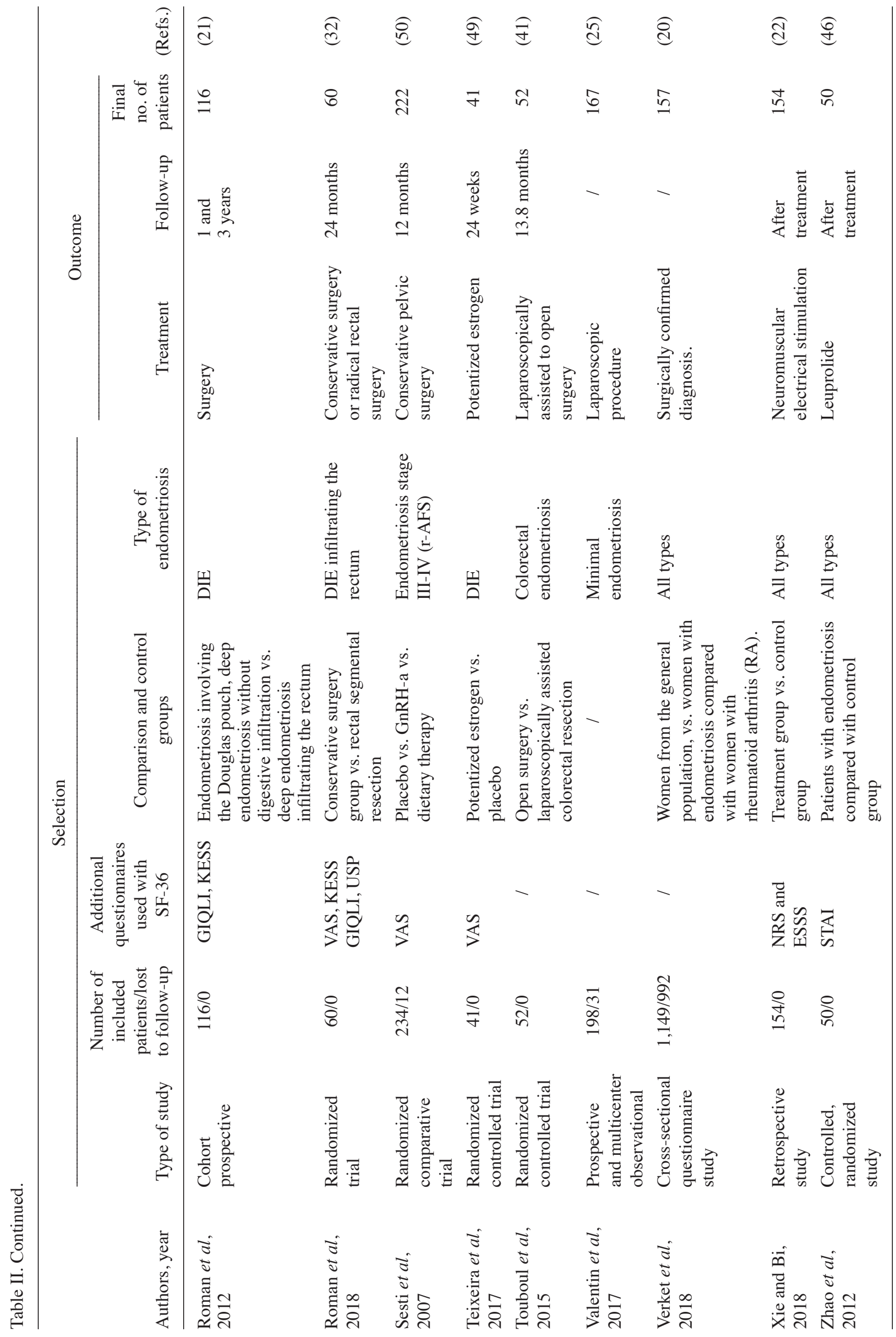




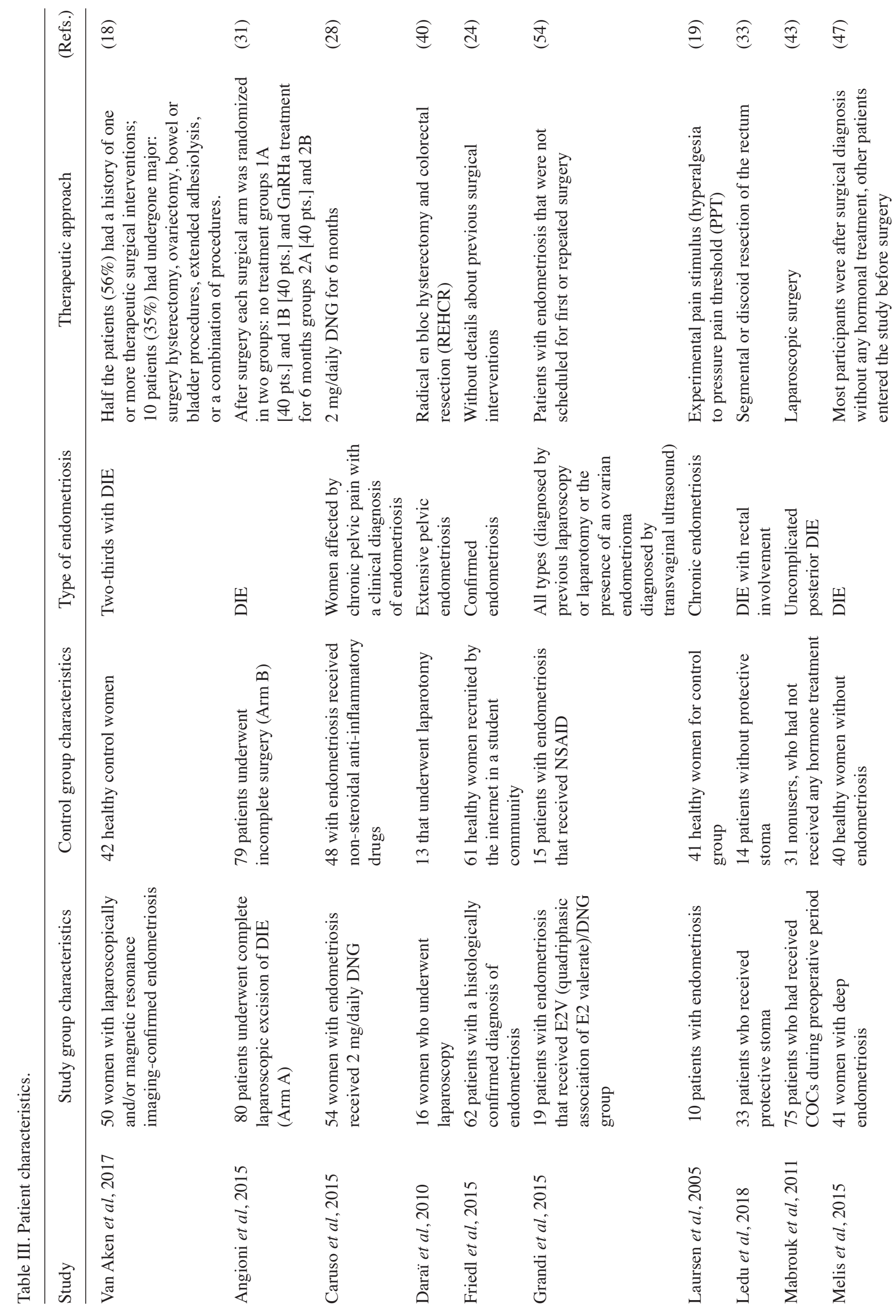




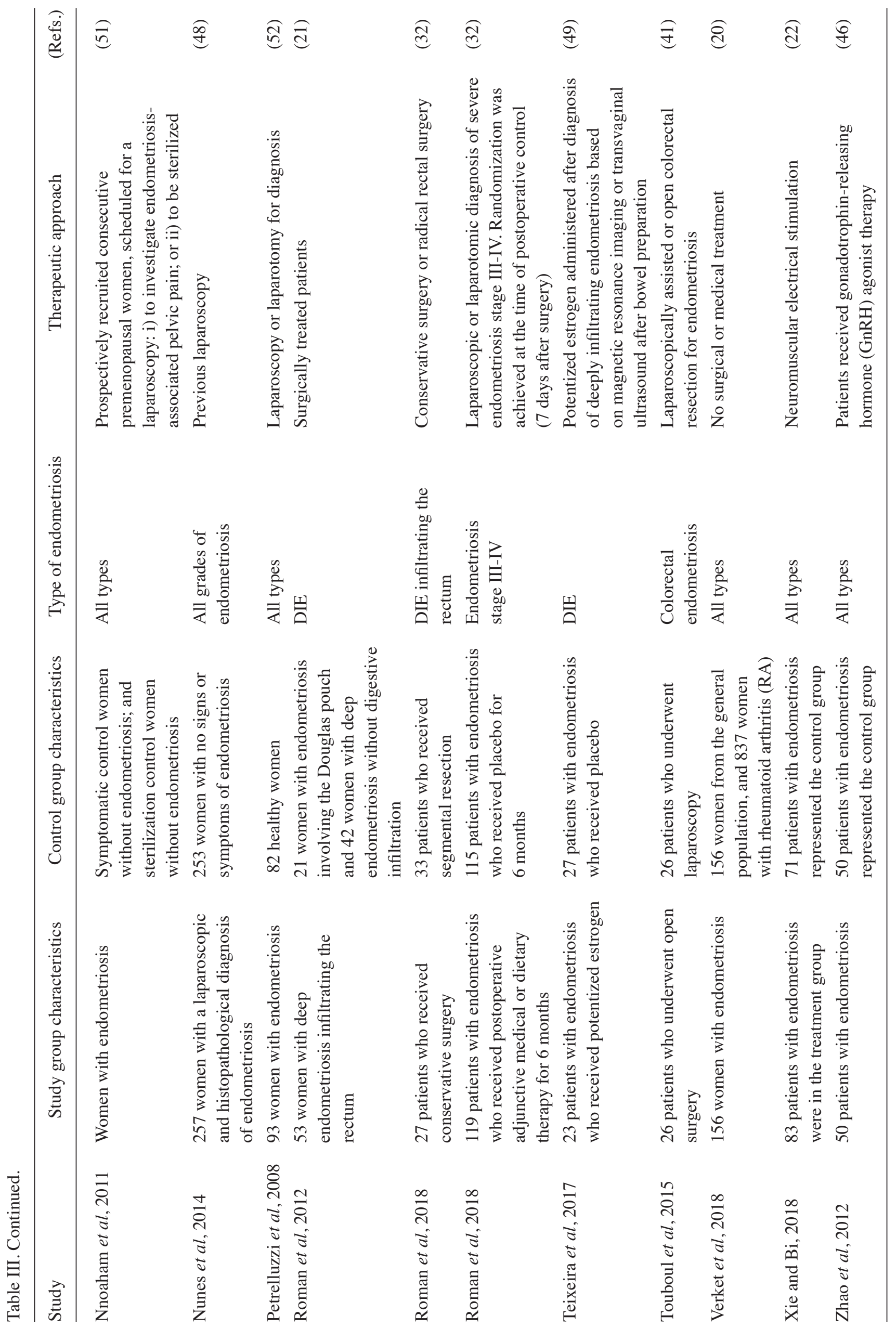


rectal resection for DIE with rectal involvement (the study results were relevant for this group).

Some authors have recommended surgery for rectosigmoid endometriosis in cases where the disease is unresponsive to conservative treatments (34-36). Daraï et al supported the finding that osteopathic manipulative therapy has a good impact on endometriosis symptoms in women with colorectal involvement (37). However, although the radical surgical approach can have a major positive impact on QOL, it does not improve all symptoms, as reported by Garavaglia et al (38). De Graaff et al concluded that many patients with endometriosis experienced better QOL and continued to have endometriosis-associated symptoms even when they were treated in tertiary care centers (39). Roman et al reported that conservative surgery should be reserved for patients with large deep rectal endometriosis (32). Daraï et al recommended laparoscopy for patients that required radical en bloc hysterectomy and colorectal resection (40). Laparoscopic colorectal resection was also indicated for cases of lower intraoperative and postoperative complications for patients with rectal endometriosis due to higher spontaneous post-surgery pregnancy rates (41). Araujo et al reported that gonadotropin-releasing hormone agonist (GnRHa) administration was followed by a temporary improvement in pain among patients with incomplete resection of deep infiltrative endometriosis (DIE), but it did not affect postsurgical pain when DIE implants were completely excised (42).

The study by Angioni et al (31) was considered for the medical treatment group because it applied postoperative randomization (of initial groups with complete or incomplete resection of endometriosis) to receivers or non-receivers of GnRHa. It selected a group with complete resection of endometriosis, which received $\mathrm{GnRH}$, and compared it with complete resection of endometriosis without medical treatment. Regarding statistics, the Caruso group (28) was not considered because it compared GnRH receivers with AINS receivers.

Mabrouk et al confirmed the role of combined oral contraceptive therapy in curbing the progression of dysmenorrhea and dyspareunia and the growth of deep endometriotic nodules (43). Meanwhile, Miller concluded that the stimulatory phase of the GnRHa therapy could be correlated with an increase in pain and a decrease in the QOL (44). Márki et al emphasized that pain management and emotion regulation strategies can be utilized for improving the QOL of patients with endometriosis. The authors suggest that it could be obtained through simultaneous application with physical treatment and psychological care (45).

Zhao et al conducted the first study to explore only the effects of psychosomatic therapy on the QOL of endometriosis patients and demonstrated that progressive muscular relaxing (PMR) training could serve as a reference for future psychosomatic interventions regarding endometriosis. PRM works efficiently for anxiety and depression related to endometriosis (46). Melis et al further suggested that a patient-centered approach that is integrated with various medical, psychological, and sexual issues should be applied in the treatment of patients with endometriosis (47).

Nunes et al compared the QOL of patients with fibromyalgia and women with and without endometriosis. The QOL of women with endometriosis showed the highest impairment (48).
Teixeira et al demonstrated that potentated estrogens significantly reduced endometriosis-associated pain compared to a placebo (49). Sesti et al demonstrated that, for endometriosis stage III-IV, QOL can be improved through postoperative hormonal suppression treatment or dietary therapy compared to surgery as well as a placebo for relieving pain (50).

Regardless of the differences across country- and ethnicity-level contexts, endometriosis was found to impair QOL and work productivity for women who continued to experience diagnostic delays in primary care (51). Even if hypocortisolism could be sometimes considered a consequence of the aversive symptoms of endometriosis, the etiopathology remains unelucidated $(52,53)$. The relationship between endometriosis and ovarian cancer was studied by Grandi et al and the preventive effect of inhibiting ovulation and menstruation was highlighted (54).

EHP-30 and SF-36 questionnaires are sensitive to changes related to endometriosis, especially correlations between increased pressure pain sensitivity and hyperalgesia and the impairment of QOL parameters, as reported by Laursen et al (19). Thus, healthcare resource allocators should focus on women with endometriosis as the disease may have a different impact for each woman (55). The SF-36 seems to be a valid instrument for evaluating QOL in women with endometriosis $(56,57)$.

In conclusion, the 36-item survey generic questionnaire, SF-36, seems to represent an efficient/valid method for assessing the QOL of patients with endometriosis who are undergoing surgical or hormonal treatments. It can be applied before and after procedures or in order to compare study groups.

\section{Acknowledgements}

Not applicable.

\section{Funding}

No funding was received.

\section{Availability of data and materials}

The information and data contained in this review and meta-analysis are documented by relevant references. Any other details can be obtained upon request.

\section{Authors' contributions}

LP and JCR performed the conceptualization of the study and had major contributions in writing the manuscript. $\mathrm{BHH}$ contributed to the methodology. MCTD and CC analyzed and interpreted the patient data. PS, III, MPR, IJB and EFS provided the formal analysis and visualization. IN, ADS and BS conducted the literature investigation and data curation. RMS provided resources and contributed to writing the manuscript (review and editing). MCTD, BS, and DS searched the literature for similar work and articles and contributed to writing the manuscript. LP and JCR supervised the study and provided project administration. All authors read and approved the final manuscript for publication. 


\section{Ethics approval and consent to participate}

Not applicable.

\section{Patient consent for publication}

Not applicable.

\section{Competing interests}

The authors declare no conflict or competing interests.

\section{References}

1. Giudice LC: Clinical practice. Endometriosis. N Engl J Med 362: 2389-2398, 2010.

2. Gustofson RL, Kim N, Liu S and Stratton P: Endometriosis and the appendix: A case series and comprehensive review of the literature. Fertil Steril 86: 298-303, 2006.

3. Practice Committee of the American Society for Reproductive Medicine: Treatment of pelvic pain associated with endometriosis: A committee opinion. Fertil Steril 101: 927-935, 2014.

4. Bodean O, Bratu O, Bohiltea R, Munteanu O, Marcu D, Spinu DA, Vacaroiu IA, Socea B, Diaconu CC, Gradinaru DF and Cirstoiu M: The efficacy of synthetic oral progestin pills in patients with severe endometriosis. Rev Chim (Bucharest) 69: 1411-1415, 2018.

5. Moradi M, Parker M, Sneddon A, Lopez V and Ellwood D: Impact of endometriosis on women's lives: A qualitative study. BMC Womens Health 14: 123, 2014

6. Bergner M: Quality of life, health status, and clinical research. Med Care 27 (Suppl 3): S148-S156, 1989.

7. Ware JE Jr and Sherbourne CD: The MOS 36-item short-form health survey (SF-36). I. Conceptual framework and item selection. Med Care 30: 473-483, 1992.

8. Yoldemir T: Quality of life for women with endometriosis: Premenopausal and postmenopausal perspectives. Climacteric 21: 411-412, 2018.

9. Kashi AM, Moradi Y, Chaichian S, Najmi Z, Mansori K, Salehin F, Rastgar A and Khateri S: Application of the World Health Organization quality of life instrument, short form (WHOQOL-BREF) to patients with endometriosis. Obstet Gynecol Sci 61: 598-604, 2018

10. Gallagher JS, DiVasta AD, Vitonis AF, Sarda V, Laufer MR and Missmer SA: The impact of endometriosis on quality of life in adolescents. J Adolesc Health 63: 766-772, 2018.

11. Fritzer N, Tammaa A, Salzer H and Hudelist G: Dyspareunia and quality of sex life after surgical excision of endometriosis: A systematic review. Eur J Obstet Gynecol Reprod Biol 173: 1-6, 2014.

12. Franck C, Poulsen MH, Karampas G, Giraldi A and Rudnicki M: Questionnaire-based evaluation of sexual life after laparoscopic surgery for endometriosis: A systematic review of prospective studies. Acta Obstet Gynecol Scand 97: 1091-1104, 2018.

13. Comptour A, Lambert C, Chauvet P, Figuier C, Gremeau AS, Canis M, Pereira B and Bourdel N: Long-term evolution of quality of life and symptoms following surgical treatment for endometriosis: Different trajectories for which patients? J Clin Med 9: 2461, 2020.

14. Liberati A, Altman DG, Tetzlaff J, Mulrow C, Gøtzsche PC, Ioannidis JP, Clarke M, Devereaux PJ, Kleijnen J and Moher D: The PRISMA statement for reporting systematic reviews and meta-analyses of studies that evaluate health care interventions: Explanation and elaboration. J Clin Epidemiol 62: e1-e34, 2009.

15. Lo CK, Mertz D and Loeb M: Newcastle-ottawa scale: Comparing reviewers' to authors' assessments. BMC Med Res Methodol 14: 45, 2014.

16. Chauvet P, Guiguet-Auclair C, Comptour A, Denouël A, Gerbaud L, Canis M and Bourdel N: Feelings and expectations in endometriosis: Analysis of open comments from a cohort of endometriosis patients. J Gynecol Obstet Hum Reprod 47 281-287, 2018

17. Arcoverde FV, Andres MP, Borrelli GM, Barbosa PA, Abrão MS and Kho RM: Surgery for endometriosis improves major domains of quality of life: A systematic review and meta-analysis. J Minim Invasive Gynecol 26: 266-278, 2019.
18. van Aken MA, Oosterman JM, van Rijn CM, Ferdek MA, Ruigt GS, Peeters BW, Braat DD and Nap AW: Pain cognition versus pain intensity in patients with endometriosis: Toward personalized treatment. Fertil Steril 108: 679-686, 2017.

19. Laursen BS, Bajaj P, Olesen AS, Delmar C and Arendt-Nielsen L: Health related quality of life and quantitative pain measurement in females with chronic non-malignant pain. Eur J Pain 9: 267-275, 2005.

20. Verket NJ, Uhlig T, Sandvik L, Andersen MH, Tanbo TG and Qvigstad E: Health-related quality of life in women with endometriosis, compared with the general population and women with rheumatoid arthritis. Acta Obstet Gynecol Scand 97: 1339-1348, 2018.

21. Roman H, Ness J, Suciu N, Bridoux V, Gourcerol G, Leroi AM, Tuech JJ, Ducrotté P, Savoye-Collet C and Savoye G: Are digestive symptoms in women presenting with pelvic endometriosis specific to lesion localizations? A preliminary prospective study. Hum Reprod 27: 3440-3449, 2012.

22. Bi XL and Xie CX: Effect of neuromuscular electrical stimulation for endometriosis-Associated pain: A retrospective study. Medicine (Baltimore) 97: e11266, 2018.

23. Comptour A, Chauvet P, Canis M, Grémeau AS, Pouly JL, Rabischong B, Pereira B and Bourdel N: Patient quality of life and symptoms after surgical treatment for endometriosis. J Minim Invasive Gynecol 26: 717-726, 2019.

24. Friedl F, Riedl D, Fessler S, Wildt L, Walter M, Richter R, Schüßler G and Böttcher B: Impact of endometriosis on quality of life, anxiety, and depression: An Austrian perspective. Arch Gynecol Obstet 292: 1393-1399, 2015.

25. Valentin L, Canis M, Pouly JL, Lasnier C, Jaffeux P, Aublet-Cuvelier B and Bourdel N: SF-36 preoperative interest of predicting improvement of quality of life after laparoscopic management of minimal endometriosis. J Gynecol Obstet Hum Reprod 46: 137-142, 2017.

26. Silveira da Cunha Araújo R, Ribeiro HS, Sekula VG, da Costa Porto BT and Ribeiro PA: Long-term outcomes on quality of life in women submitted to laparoscopic treatment for bowel endometriosis. J Minim Invasive Gynecol 21: 682-688, 2014

27. Bassi MA, Podgaec S, Dias JA Jr, Filho ND, Petta CA and Abrao MS: Quality of life after segmental resection of the rectosigmoid by laparoscopy in patients with deep infiltrating endometriosis with bowel involvement. J Minim Invasive Gynecol 18: 730-733, 2011.

28. Caruso S, Iraci M, Cianci S, Casella E, Fava V and Cianci A: Quality of life and sexual function of women affected by endometriosis-associated pelvic pain when treated with dienogest. J Endocrinol Invest 38: 1211-1218, 2015.

29. Dubernard G, Rouzier R, David-Montefiore E, Bazot M and Daraï E: Use of the SF-36 questionnaire to predict quality-of-life improvement after laparoscopic colorectal resection for endometriosis. Hum Reprod 23: 846-851, 2008.

30. Ribeiro PA, Sekula VG, Abdalla-Ribeiro HS, Rodrigues FC, Aoki T and Aldrighi JM: Impact of laparoscopic colorectal segment resection on quality of life in women with deep endometriosis: One year follow-up. Qual Life Res 23: 639-643, 2014.

31. Angioni S, Pontis A, Dessole M, Surico D, De Cicco Nardone C and Melis I: Pain control and quality of life after laparoscopic en-block resection of deep infiltrating endometriosis (DIE) vs. incomplete surgical treatment with or without $\mathrm{GnRHa}$ administration after surgery. Arch Gynecol Obstet 291: 363-370, 2015.

32. Roman H, Bubenheim M, Huet E, Bridoux V, Zacharopoulou C, Daraï E, Collinet $\mathrm{P}$ and Tuech JJ: Conservative surgery versus colorectal resection in deep endometriosis infiltrating the rectum: A randomized trial. Hum Reprod 33: 47-57, 2018

33. Ledu N, Rubod C, Piessen G, Roman H and Collinet P. Management of deep infiltrating endometriosis of the rectum: Is a systematic temporary stoma relevant? J Gynecol Obstet Hum Reprod 47: 1-7, 2018.

34. Riiskjr M, Forman A, Kesmodel US, Andersen LM, Ljungmann K and Seyer-Hansen M: Pelvic pain and quality of life before and after laparoscopic bowel resection for rectosigmoid endometriosis: A prospective, observational study. Dis Colon Rectum 61: 221-229, 2018.

35. Constantin V, Carăp A, Bobic S, Pâun S, Brâtilâ S, Socea B, Morosanu AM and Mirancea N: Accurate diagnosis of sigmoid colon endometriosis by immunohistochemistry and transmission electron microscopy-a case report. Chirurgia 110: 482-485, 2015.

36. Mabrouk M, Spagnolo E, Raimondo D, D'Errico A, Caprara G, Malvi D, Catena F, Ferrini G, Paradisi R and Seracchioli R: Segmental bowel resection for colorectal endometriosis: Is there a correlation between histological pattern and clinical outcomes? Hum Reprod 27: 1314-1319, 2012. 
37. Daraï C, Bendifallah S, Foulot H, Ballester M, Chabbert-Buffet N and Daraï E: Impact of osteopathic manipulative therapy in patient with deep with colorectal endometriosis: A classification based on symptoms and quality of life. Gynecol Obstet Fertil Senol 45: 472-477, 2017 (In French).

38. Garavaglia E, Inversetti A, Ferrari S, De Nardi P and Candiani M: Are symptoms after a colorectal segmental resection in deep endometriosis really improved? The point of view of women before and after surgery. J Psychosom Obstet Gynecol 39: 248-251, 2018.

39. De Graaff AA, D'Hooghe TM, Dunselman GA, Dirksen CD and Hummelshoj L; WERF EndoCost Consortium; Simoens S: The significant effect of endometriosis on physical, mental and social wellbeing: Results from an international cross-sectional survey. Hum Reprod 28: 2677-2685, 2013.

40. Daraï E, Ballester M, Chereau E, Coutant C, Rouzier R and Wafo E: Laparoscopic versus laparotomic radical en bloc hysterectomy and colorectal resection for endometriosis. Surg Endosc 24: 3060-3067, 2010.

41. Touboul C, Ballester M, Dubernard G, Zilberman S, Thomin A and Daraï E: Long-term symptoms, quality of life, and fertility after colorectal resection for endometriosis: Extended analysis of a randomized controlled trial comparing laparoscopically assisted to open surgery. Surg Endosc 29: 1879-1887, 2015.

42. Araujo D, Passos RB, Souza CP, Silva AP and Marques M: Cost effectiveness analysis of goserelin empiric therapy for deep endometriosis treatment. Value in health 12: A164, 2009.

43. Mabrouk M, Frascà C, Geraci E, Montanari G, Ferrini G, Raimondo D, Alvisi S, Paradisi R, Villa G and Seracchioli R: Combined oral contraceptive therapy in women with posterior deep infiltrating endometriosis. J Minim Invasive Gynecol 18: 470-474, 2011

44. Miller JD: Quantification of endometriosis-associated pain and quality of life during the stimulatory phase of gonadotropinreleasing hormone agonist therapy: A double-blind, randomized, placebo-controlled trial. Am J Obstet Gynecol 182: 1483-1488, 2000.

45. Márki G, Bokor A, Rigó J and Rigó A: Physical pain and emotion regulation as the main predictive factors of health-related quality of life in women living with endometriosis. Hum Reprod 32: 1432-1438, 2017.

46. Zhao L, Wu H, Zhou X, Wang Q, Zhu W and Chen J: Effects of progressive muscular relaxation training on anxiety, depression and quality of life of endometriosis patients under gonadotrophinreleasing hormone agonist therapy. Eur J Obstet Gynecol Reprod Biol 162: 211-215, 2012

47. Melis I, Litta P, Nappi L, Agus M, Melis GB and Angioni S: Sexual function in women with deep endometriosis: Correlation with quality of life, intensity of pain, depression, anxiety, and body image. Int J Sex Heal 27: 175-185, 2015.
48. Nunes FR, Ferreira JM and Bahamondes L: Prevalence of fibromyalgia and quality of life in women with and without endometriosis. Gynecol Endocrinol 30: 307-310, 2014.

49. Teixeira MZ, Podgaec S and Baracat EC: Potentized estrogen in homeopathic treatment of endometriosis-associated pelvic pain: A 24-week, randomized, double-blind, placebo-controlled study. Eur J Obstet Gynecol Reprod Biol 211: 48-55, 2017.

50. Sesti F, Pietropolli A, Capozzolo T, Broccoli P, Pierangeli S, Bollea MR and Piccione E: Hormonal suppression treatment or dietary therapy versus placebo in the control of painful symptoms after conservative surgery for endometriosis stage III-IV. A randomized comparative trial. Fertil Steril 88: 1541-1547, 2007.

51. Nnoaham KE, Hummelshoj L, Webster P, d'Hooghe T, de Cicco Nardone F, de Cicco Nardone C, Jenkinson C, Kennedy SH and Zondervan KT; World Endometriosis Research Foundation Global Study of Women's Health consortium: Impact of endometriosis on quality of life and work productivity: A multicenter study across ten countries. Fertil Steril 96: 366-373, 2011.

52. Petrelluzzi KFS, Garcia MC, Petta CA, Grassi-Kassisse DM and Spadari-Bratfisch RC: Salivary cortisol concentrations, stress and quality of life in women with endometriosis and chronic pelvic pain. Stress 11: 390-397, 2008.

53. Matei AM, Draghici-Ionescu AM, Cioplea M, Zurac SA, Boda D, Serban I, Caruntu C, Ilie MA and Fekete LG: Skin endometriosis: A case report and review of the literature. Exp Ther Med 21: 532, 2021

54. Grandi G, Toss A, Cortesi L, Botticelli L, Volpe A and Cagnacci A: The association between endometriomas and ovarian cancer: preventive effect of inhibiting ovulation and menstruation during reproductive life. Biomed Res Int 2015: 751571, 2015.

55. Lövkvist L, Boström P, Edlund M and Olovsson M: Age-related differences in quality of life in Swedish women with endometriosis. J Womens Health (Larchmt) 25: 646-653, 2016.

56. Jones G, Jenkinson C and Kennedy S: The impact of endometriosis upon quality of life: A qualitative analysis. J Psychosom Obstet Gynaecol 25: 123-33, 2004.

57. Bourdel N, Chauvet P, Billone V, Douridas G, Fauconnier A, Gerbaud L and Canis M: Systematic review of quality of life measures in patients with endometriosis. PLoS One 14: $\mathrm{e} 0208464,2019$

This work is licensed under a Creative Commons Attribution-NonCommercial-NoDerivatives 4.0 International (CC BY-NC-ND 4.0) License. 